\title{
Identification of dominant lactic acid bacteria isolated from grape juices. Assessment of its biochemical activities relevant to flavor development in wine
}

\author{
This article was published in the following Dove Press journal: \\ International Journal of Wine Research \\ 5 June 2009 \\ Number of times this article has been viewed
}

\author{
Fabiana Maria Saguir ${ }^{1,3}$ \\ Iris Eleonora Loto Campos' \\ Carmen Maturano' \\ Maria Cristina Manca de \\ Nadra ${ }^{1,2,3}$ \\ 'Facultad de Bioquímica, Química y \\ Farmacia, Universidad Nacional de \\ Tucumán, Tucumán, Argentina; ${ }^{2}$ Centro \\ de Referencia para Lactobacilos (Cerela), \\ Tucumán, Argentina; ${ }^{3}$ Career Investigators \\ from Consejo Nacional de Investigaciones \\ Científicas y Técnicas, Argentina
}

Abstract: We investigated the dominant lactic acid bacteria (LAB) from grape juice and commencement of malolactic fermentation (MLF) samples of a cellar located in Argentina and assessment of its $\beta$-glucosidase activity and butter aroma compounds production. LAB number found in grape juice (approximately $\log _{10} 3.3$ ) was lower than that obtained in the MLF samples. Oenococcus oeni was predominant, accounting for $68 \%$ of the 81 LAB isolated. Majority of whole cells derived from $O$. oeni cultures at the end of the exponential growth showed detectable $\beta$-glucosidase activity. Contrarily, the highest proportion of them did not produce diacetyl, acetoin, and 2,3-butylene glycol. A direct relation between both properties among the $O$. oeni strains could not be established. In the selected MS25 strain, L-malic acid was compatible with good enzyme activity and was partially able to annul the negative influence of the low $\mathrm{pH}(3.8)$. In different conditions, the aroma compounds were lower than $4 \mathrm{mg} / \mathrm{ml}$, especially at $\mathrm{pH} 3.8$ and in presence of L-malic acid (2.5 g/l). This strain could have adequate characteristics for potential use in winemaking. Finally, the assessment of both biochemical properties in $O$. oeni should be considered as a quality criterion for selecting starter cultures for the improvement of the wines aroma.

Keywords: isolation, lactic acid bacteria, biochemical properties, aroma, wine

\section{Introduction}

Lactic acid bacteria (LAB) are widely used in food biotechnology and efficient control of these microbiological processes requires an increase in our knowledge about their ecology and biochemical activities. LAB occur naturally on grapes and their ability to grow in wine had been documented. ${ }^{1,2}$ LAB associated with the wine making process belongs to the genera Lactobacillus, Leuconostoc, Oenococcus, and Pediococcus. ${ }^{3-5}$ Malolactic fermentation (MLF) induced by LAB, after alcoholic fermentation (AF), is a suitable process for correct wine acidity. It consists of the L-malic acid decarboxylation to lactic acid, resulting in a wine with a softer mouth feel. At the same time, the MLF provides stability for wines to be aged and the addition of flavors by modifying fruitderived aromas and producing aroma-active compounds. ${ }^{1,6}$

One of the most evident flavor changes is the development of a 'buttery' or 'butterscotch' character. Diacetyl has been attributed to being a major contributor to this buttery character in wine. ${ }^{7,8}$ This metabolite can be formed from citric acid in wine. Saguir and Manca de Nadra ${ }^{9}$ demonstrated that L-malic and citric acids favored wine Oenococcus oeni strain growth in nutritional stress conditions and that,
Correspondence: Fabiana Maria Saguir Facultad de Bioquímica, Química y Farmacia, Universidad Nacional de Tucumán, Ayacucho 49I, 4000 Tucumán, Argentina

Tel $+5438 I 425 I 425$

Fax +54 38I 43I I72/400 5600

Email fabianasaguir@fbqf.unt.edu.ar 
specifically, citric acid was involved in the biosynthesis of the aspartate-derived essential amino acids. Bartowsky and Henschke, ${ }^{8}$ reported that in wine the diacetyl concentration is generally low relative to its flavor threshold and appears to be important to determining wine style. Yeast are also able to synthesize diacetyl during the AF, however, the majority of it is further metabolized to acetoin and 2,3-butanediol. ${ }^{10}$

In the last decades, increased interest has been focused on glycosidic enzymes as a means of flavor modification of wine. ${ }^{11}$ In fact, these enzymes hydrolyze glycoconjugated precursors, releasing active aroma compounds such as straight-chain alcohols, norisoprenoids and free phenols. These odorous compounds may occur in a free form in grapes, or bounded to sugar molecules $(\beta$-D-glucose or a dissacharide comprising glucose and a second sugar unit being $\alpha$-L-arabinofuranose, $\alpha$-L-rhamnopyranose or $\beta$-D-apiofuranose) to form an odorless nonvolatile glycosidic complexes. ${ }^{12}$ Volatile compounds, present as monoglucosides are liberated via $\beta$-D-glucosidase (glucopyranosidase), whereas diglycoside-bound aglycones are liberated through a sequential release by different glucosidase followed by $\beta$-D-glucosidase. ${ }^{13}$

Much attention has been paid to Saccharomyces cerevisiae (given its importance in wine-making) but this yeast showed very limited glycosidases production, much of which are intracellular. ${ }^{14}$ In addition, they are unstable at wine $\mathrm{pH}$ and may be inhibited by high sugar and ethanol concentrations. ${ }^{14}$ On the other hand, Aspergillus sp. is a common source of commercial enzyme preparations that have glycosidic activities; however, these preparations are often impure, requiring resolution before characterization in the laboratory, and they have undesirable effects on the wine. ${ }^{15}$ Grapevines produce glycosidases, although these enzymes have little activity against wine glycosides. ${ }^{16}$ Thus, strains of LAB well suited to perform the MLF might be a good source of glycosidases. Changes in the glycoside content of Tannat wines during MLF indirectly supported the existence of such activities in the commercial $O$. oeni strains used. ${ }^{17}$ More specific data has come from examinations of commercial wines. O. oeni isolates, ${ }^{18,19}$ which were shown to have the potential for high glycosidase activity against nitrophenyl glycosides. While the use of enzymes and/or selected cultures to liberate aroma compounds from natural grape aroma glycosides is still in the development stage, the findings to date for LAB justify further investigation. On the other hand, no information was reported about some relation between diacetyl production and $\beta$-glucosidase activities by wine LAB.
The aim of this work was to investigate the dominant LAB isolated from grape juice and fermented musts at commencement of MLF in a cellar located in north of Argentina and further, to assess its biochemical properties, such as $\beta$-glucosidase activity and butter aroma compounds production, that may be relevant to flavor development in wine. At the same time, the influence of some wine parameters on the growth and metabolism of a selected $O$. oeni strain was analyzed.

\section{Materials and methods Microorganism}

Oenococcus oeni strains isolated and identified during this study from grape juice and fermented musts were stored at $-20{ }^{\circ} \mathrm{C}$ in de Man Rogosa Sharpe (MRS) medium (Oxoid Ltd., London, England) with 15\% (v/v) tomato juice (TJ) supplemented with glycerol $(30 \%, \mathrm{v} / \mathrm{v})$.

\section{Samples}

Samples were collected aseptically in one cellar at Cafayate, a region located in North of Argentina. Samples consisted of natural juice from red grapes (Malbec variety) and the musts collected on the completion of AF carried out by indigenous or commercial yeast cultures, before MLF had commenced. The $\mathrm{pH}$ and ethanol concentration of wine samples were 3.4 and $12 \%$, respectively.

Generally, sample volumes of $500 \mathrm{ml}$ were taken from large tanks, transferred to a sterile glass container, and transported to the laboratory under refrigeration $\left(4^{\circ} \mathrm{C}\right)$.

\section{Processing, enumeration, and isolation of LAB from samples}

For enumeration and isolation of LAB contained in the samples, $1.0 \mathrm{ml}$-aliquots (diluted if necessary) were plated on MRS agar (Oxoid Ltd.) enriched with fructose ( $5 \mathrm{~g} / \mathrm{l})$ and L-malic acid ( $3 \mathrm{~g} / \mathrm{l})$ and adjusted to $\mathrm{pH}$ 5.0. The isolating MRS medium was supplemented with two $\mu \mathrm{g} / \mathrm{ml}$ of cycloheximide (MRS-C; Sigma, St. Louis, MO, USA) to suppress the growth of yeasts. At the same time, aerobic mesophilic microflora was determined on plate count agar (PCA; Oxoid Ltd.).

Agar MRS-C plates were incubated anaerobically (BBL GasPak Anaerobic System; Becton Dickinson Argentina, Buenos Aires, Argentina) and PCA plates aerobically at $30{ }^{\circ} \mathrm{C}$ for 10 days before enumeration. The PCA agar plates were flooded after enumeration with $3 \% \mathrm{H}_{2} \mathrm{O}_{2}$ in order to observe the presence for catalase positive colonies.

In addition, for all samples, isolations on MRS-C agar media were prepared from enrichment cultures conducted in 
MRS broth, pH 5.0 (containing cycloheximide as mentioned above) after five days of incubation (when microbial growth became evident).

A total of 72 colonies ( 24 isolates from each analyzed sample) by random selection were picked up from MRS-C media. A small number of nine isolates were also obtained from PCA media. The isolates were purified by sub-culturing in MRS broth with TJ (15\% v/v), pH 4.8 at $30^{\circ} \mathrm{C}$ and further characterized. All LAB strains were maintained at $-20{ }^{\circ} \mathrm{C}$ in MRS with TJ (15\% v/v) and glycerol $(20 \% \mathrm{v} / \mathrm{v})$, and grown anaerobically at $30{ }^{\circ} \mathrm{C}$ in MRS with TJ (15\%).

\section{Phenotypical characterization of isolates}

The isolates were characterized for Gram and catalase reaction, cell shape, cytochrome-oxidase activity, spore formation, production of ammonia from arginine, ${ }^{20}$ and fermentative catabolism of glucose. Gas and D- or L-lactic acid isomers production from glucose metabolism were determined in Gibson medium, ${ }^{21}$ and by using an enzymatic method with Boehringer Kit (Boehringer, Mannheim, Germany), respectively.

Ability of growth, under microaerophilic conditions in BBL GasPak jars (Becton Dickinson Argentina), in which the content of oxygen was reduced by use of a lighted candle, was determined on MRS agar plates incubated at $15^{\circ} \mathrm{C}, 30^{\circ} \mathrm{C}$, $37^{\circ} \mathrm{C}$, and $45^{\circ} \mathrm{C}$. Ability of growth at different $\mathrm{NaCl}$ concentrations $(2 \%, 4 \%, 6 \%$ and $8 \% \mathrm{w} / \mathrm{v})$ and $\mathrm{pH}$ values $(4,5,5.5$, and 6.5) were also investigated. Studies of fermentation of carbohydrates and related compounds were carried out using API 50 CH galleries (BioMérieux, Marcy-l'Etoile, France).

\section{Genotypical characterization by PCR with species-specific primers}

Preparation of bacteria for the polymerase chain reactions (PCR) involved growing on MRS medium (Oxoid Ltd.) with TJ (15\%) and adjusted at pH 4.8. The DNA extraction was prepared as described by Reguant and Bordons. ${ }^{4}$ Concentration of the DNA obtained was estimated by electrophoresis in one $\%(\mathrm{w} / \mathrm{v})$ agarose gel with Tris-acetate-EDTA buffer (TAE) (Sigma).

Oenococcus oeni strains were identified by the speciesspecific PCR method, ${ }^{22}$ which amplifies a fragment of the malolactic enzyme gene of $O$. oeni. A thermocycler machine (Biometra, Goettingen, Germany) was used for PCR reactions. The $20 \mu \mathrm{l}$ PCR reaction mix consisted of $0.4 \mu \mathrm{M}$ of each, On1 and On2 primer, ${ }^{22} 0.2 \mathrm{mM}$ of each dNTP (Amersham Pharmacia Biotech, Inc., Piscataway, NJ, USA), $2 \mathrm{mM}$ of $\mathrm{MgCl}_{2}, 2 \mu \mathrm{l}$ of $10 \mathrm{x}$ reaction buffer (Amersham Pharmacia Biotech, Inc.), 0.5 U Taq DNA polymerase (Amersham Pharmacia Biotech, Inc.), and $10 \mathrm{ng}$ of genomic DNA. The amplification profile was: one cycle at $94{ }^{\circ} \mathrm{C}$ for $5 \mathrm{~min}, 30$ cycles of $94{ }^{\circ} \mathrm{C}$ for $1 \mathrm{~min}, 64^{\circ} \mathrm{C}$ for $2 \mathrm{~min}$, and $72{ }^{\circ} \mathrm{C}$ for $2 \mathrm{~min}$. A final extension of $72^{\circ} \mathrm{C}$ for $10 \mathrm{~min}$ was also included. The amplification products were visualized by ethidium bromide $(5 \mu \mathrm{g} / \mathrm{ml})$ staining after gel electrophoresis.

\section{Analytical methods}

D-Glucose was analyzed by the glucose oxidase method (Kit from Wiener Laboratory, Rosario, Argentina) and L-malic acid by enzymatic methods (Boheringer Kits; Boheringer). Diacetyl, acetoin and 2,3-butanediol was analyzed as a combined value according to the colorimetric method of Hill and colleagues, ${ }^{23}$ modified by Branen and Keenan. ${ }^{24}$

\section{$\beta$-glicosidase activity}

Enzyme assays were conducted on whole cells and supernatants obtained by centrifugation (4000 $\mathrm{g}$ for $20 \mathrm{~min}$ ) of cultures grown in MRS with TJ (15\%), under different conditions, as mentioned in the text, in anaerobic conditions at $30{ }^{\circ} \mathrm{C}$ at the final of the exponential growth phase. Enzymatic activity was measured according to D'Incecco and colleagues, ${ }^{13}$ using $p$-nitrophenyl- $\beta$-D-glucopyranoside ( $p$-NPG) (Sigma cat no. N7006) as substrate. The assay was performed for $30 \mathrm{~min}$ at $37^{\circ} \mathrm{C}$, after which $400 \mu \mathrm{l}$ of $1 \mathrm{M}$ sodium carbonate solution was added to stop the reaction and allow the development of the yellow color of the $p$-nitrophenolate ion; the samples were then centrifuged. The assay was read against the blank at $400 \mathrm{~nm}$ in a spectrophotometer (Spectronic Genesys 5; Milton Roy Company, Rochester, NY, USA) in a $1 \mathrm{~cm}$ cell.

The enzymatic activity was expressed as U/g equivalent to $\mu$ moles $p$-nitrophenyl released by min and gram of dry weight of cells.

\section{Statistical analysis}

The experimental data were analyzed by one-way analysis of variance test. Variable means showing statistical significance were compared using Tukey's test (Minitab student R12). All statements of significance are based on the 0.05 level of probability. ${ }^{25}$ Three replicate determinations were carried out.

\section{Results}

\section{Isolation and identification of LAB}

Determined on selective agar MRS-C media by direct plate culture, the samples of grape juice and fermented musts contained levels of LAB ranging from $\log 2.9$ to $\log 4.4 \mathrm{cfu} / \mathrm{ml}$. 
There was less LAB present in grape juice $(3.30 \mathrm{cfu} / \mathrm{ml})$ than in the samples corresponding to commencement of MLF (4.45 and $4.40 \mathrm{cfu} / \mathrm{ml}$ when AF was conducted by indigenous or commercial yeasts, respectively).

In grape juice, a count of approximately $1.5 \mathrm{log}$ cycles higher was observed by use of PCA. The majority of colonies on this medium corresponded to yeasts (in the order of $10^{4} \mathrm{cfu} / \mathrm{ml}$ ) and in a lesser extent to LAB. Non-LAB with reaction of Gram and catalase positives was also detected. By contranst, in the samples from beginning of MLF no significant differences in the counts on PCA as regards to MRS-C plates were observed. Moreover, on PCA the majority of colonies were small, grey or white, catalase-negative, Gram-positive able to grow under aerobic conditions suggesting they were LAB.

In any assayed conditions Gram-negative, catalasepositive bacteria belonging to Enterobacteriaceae were observed.

On the other hand, when enrichment cultures were used before isolating the presence of LAB, increased significantly (in order $10^{6}$ or $10^{8} \mathrm{cfu} / \mathrm{ml}$, depending on the samples used). Similar result was described by Bae and colleagues ${ }^{26}$ for LAB isolation from wine grapes.

A total of 72 isolates belonging to LAB group were selected from MRS-C agar media. In addition, nine isolates were obtained from PCA plates (of a total of 81 isolates, 27 corresponded to each analyzed sample). All LAB isolates were Gram-positive, catalase-negative, nonspore-forming, nonmotile cells, and exhibited a fermentative catabolism from carbohydrates. They were obligatory heterofermentative accounting for $74 \%$ of the total analyzed strains and exhibited the following characteristics: production of gas and D-lactic acid isomer from glucose, no ammonia formation from arginine, growth at $15^{\circ} \mathrm{C}$ but no growth at $45^{\circ} \mathrm{C}$ and cocci arranged in chains. Ninety-two percent of isolates belonging to this group were classified as $O$. oeni on the basis that they grew in presence of $10 \%$ ethanol, acid $\mathrm{pH}$ and at $30{ }^{\circ} \mathrm{C}$ or $37^{\circ} \mathrm{C}$ and by using of the API $50 \mathrm{CH}$ kit. The homofermentative isolates ( $26 \%$ of the total LAB studied) were mainly characterized as Lactobacillus sp. and in a lesser extent as Pediococcus sp.

As shown in Figure 1 we observed, that in grape juice O. oeni was found to a lesser extent (about 15\% lower) than other LAB species such as Leuconostoc, Lactobacillus, and Pediococcus sp. However, at commencement of MLF independently, of the wild or commercial yeast type employed for conducing AF, almost all isolates were identified as $O$. oeni accounting for $78 \%$ and $85 \%$, respectively.

A single product of about $1025 \mathrm{bp}$, the expected size of the malolactic enzyme gene fragment to be amplified, was obtained only when purified DNA from $O$. oeni isolates phenotypically identified and the reference strain were used as target for specific PCR reaction. Only one of them did not show this positive result and it was excluded from

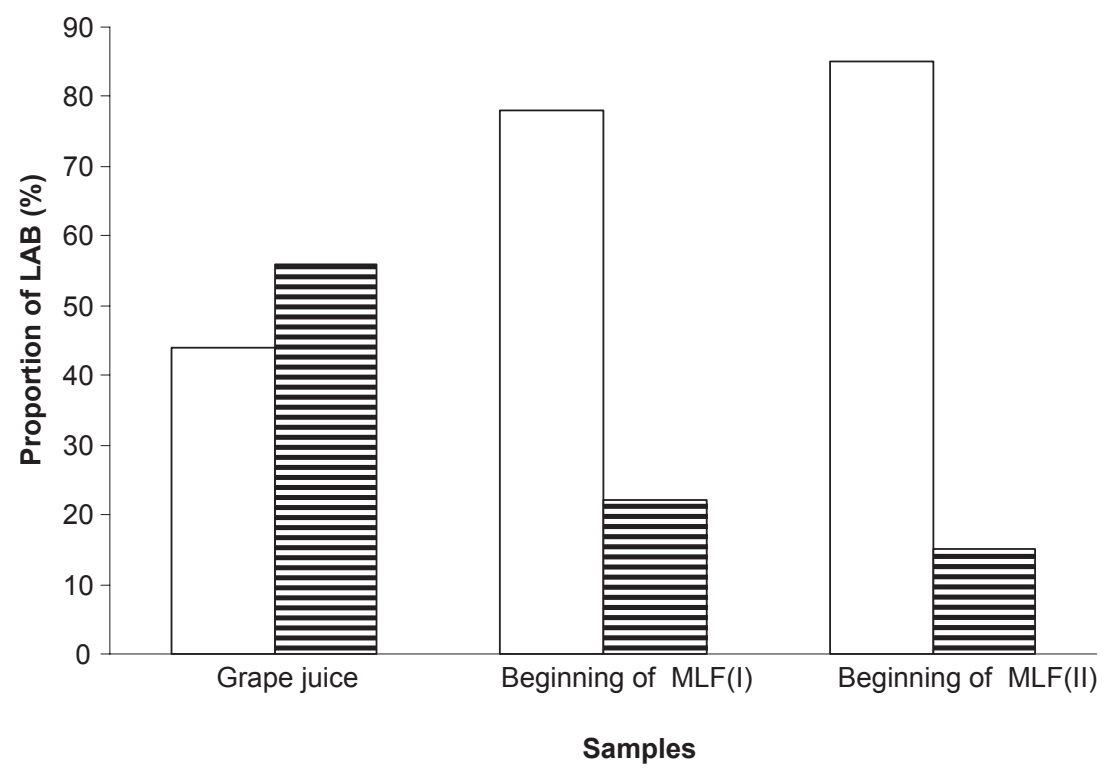

Figure I Proportion of Oenococcus oeni and other LAB species isolated from grape juice and samples from commencement of MLF, after AF conducted by indigenous yeasts ( $\mathrm{I}$ ) or yeast starter culture (II).

Key: ( $\square$ ) Oenococcus oeni; ( $\equiv)$ other LAB than Oenococcus oeni.

Abbreviations: AF, alcoholic fermentation; LAB, lactic acid bacteria; MLF, malolactic fermentation. 
this group. Strains of other species than $O$. oeni gave negative reaction (Figure 2 ).

\section{Growth and $\mathrm{pH}$ variation of 0 . oeni strains identified during this study}

A total of 54 strains of $O$. oeni, identified during this study were transferred to complex laboratory medium and their maximum population levels and $\mathrm{pH}$ values obtained at the end of exponential growth, were determined (Table 1). The extent of bacterial growth varied according to the analyzed strain and it was directly related with the $\mathrm{pH}$ diminution. The majority of the strains grew to optical densities (OD) at $560 \mathrm{~nm}$ of among 0.66 and 1.00. Thirty-seven percent did not show significant differences $(P<0.05)$ but reached an average final population of $\mathrm{OD}_{560 \mathrm{~nm}}: 0.85$. Eight strains of the total of $O$. oeni studied showed the highest population levels with an average value of $\mathrm{OD}_{560 \mathrm{~nm}}: 1.2$. One strain that did not show significant difference with those classified as ${ }^{\mathrm{bc}}$ reached the lowest bacterial population level. We focused our attention on those strains of $O$. oeni that were able to achieve growth at absorbance values higher than 0.7 to further investigations. So the strains $(11 \%)$ classified as ${ }^{\mathrm{c}}$, or ${ }^{\mathrm{bc}}$ were excluded.

\section{$\beta$-glucosidase activity in 0 . oeni strains}

Table 2 shows the $\beta$-glucosidase activities of whole cells of the $O$. oeni strains obtained from cultures in MRS medium with $\mathrm{TJ}, \mathrm{pH} 4.8$, at the end of the exponential growth phase. Majority of tested strains (73\%) possessed a detectable and variable level of $\beta$-glucosidase activity. Only whole cells

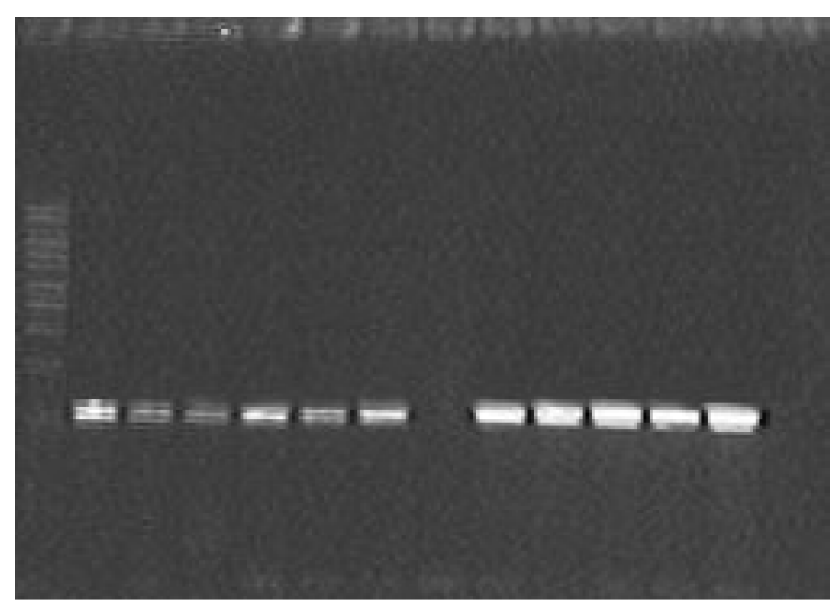

Figure 2 Profiles obtained with PCR primers On I and On2 of Oenococcus oeni isolated from of fermented must at commencement of MLF in agarose gel $1.5 \%$. Line one: marker of DNA molecular weight I kb, Lines 2-12: strains phenotypically identified as Oenococcus oeni, Line 13: Oenococcus oeni $X_{2}$ L, control positive, Lines 14-15: strains of Lactobacillus and Leuconostoc sp., controls negative.

Abbreviations: MLF, malolactic fermentation; PCR, polymerase chain reaction. derived from 13 out of the 48 strains studied failed to show this enzymatic activity. According to the extent of $\beta$-glucosidase activity, they were arbitrary classified into three groups: From one to $20 \mathrm{U} / \mathrm{g}$ the enzymatic activity was considered as low, from 20 to $60 \mathrm{U} / \mathrm{g}$ it was considered as intermediary and for $>60 \mathrm{U} / \mathrm{g}$ it was considered as high. Majority of isolates with a detectable activity presented an intermediary level accounting for $40 \%$ with an average minimum and maximum value of activity that corresponded to $43.23 \pm 2.78,28.32 \pm 2.11$, and $53.86 \pm 5.13 \mathrm{U} / \mathrm{g}$, respectively (Table 2 ). Twelve isolates, which correspond to a percentage of $34.3 \%$ of the total of positive strains for enzymatic activity showed low activity levels and only nine strains, produced high levels of $\beta$-glucosidase enzyme. It is interesting to note that no strains from grape juice (MS1-MS11) corresponded to this last group. Thus, all strains classified as high activity were isolated in a similar proportion from both samples of commencement of MLF. Moreover, of the total of the $O$. oeni isolates with detectable levels of activity 6,13 , and 15 strains corresponded to collected samples from grape juice, begining of MLF after AF by wild or commercial yeast cultures, respectively.

Because no activities were found in the supernatants of all the analyzed cultures, $\beta$-glucosidase enzyme was not thought to be extracellular in this bacterium.

\section{$\mathrm{C}_{4}$ aroma compounds formation by 0 . oeni}

Diacetyl, acetoin, and 2,3-butilenglycol formation by $O$. oeni strains in MRS supplemented with TJ, pH 4.8 at the end of exponential growth phase was investigated. No butter aroma compounds production was detected in the majority of the analyzed strains (60.4\%) and in the cells resting their formation ranged from 0.23 to $25.61 \mathrm{mg} / 1$ (Figure 3 ). This ability was also distributed at a higher frequency in those strains isolated from samples of commencement of MLF (after AF conduced by wild or commercial yeasts) than grape juice and accounting for $42.9 \%, 38.1 \%$, and $9 \%$, respectively.

Thus, whilst the enzymatic activity was detectable in the majority of the isolates studied $(76 \%)$, the $\mathrm{C}_{4}$ aroma compounds formation only occurred in $39 \%$ of them. Table 3 shows that the largest size of population that did not produce any studied $\mathrm{C}_{4}$ aroma compounds produced mainly intermediary levels of $\beta$-glucosidase activities whilst most of the strains that formed $\mathrm{C}_{4}$ aroma compounds in concentrations equal or lower than $4.4 \pm 0.22 \mathrm{mg} / 1 \mathrm{did}$ not present $\beta$-glucosidase activity or showed it at high levels. Of isolates, $5.5 \%$ formed diacetyl, acetoin, and 2,3-butilenglycol in concentrations equal or higher than $9 \pm 0.49 \mathrm{mg} / 1$ and were mainly unable to produce detectable enzyme levels. 
Table I Growth of Oenococcus oeni isolates in MRS medium supplemented with TJ (I5\%) and pH variation

\begin{tabular}{|c|c|c|c|c|c|}
\hline Strain & Maximum population* & Final pH & Strain & Maximum population* & Final pH \\
\hline MSI & $0.87 \pm\left. 0.0\right|^{\text {afid }}$ & $4.46 \pm 0.01$ & MS29 & $0.92 \pm 0.0 \mathrm{I}^{\mathrm{fid}}$ & $4.39 \pm 0.01$ \\
\hline MS2 & $0.68 \pm 0.0 \mathrm{l}^{\mathrm{bc}}$ & $4.55 \pm 0.07$ & MS30 & $0.87 \pm 0.0 l^{\text {afid }}$ & $4.45 \pm 0.07$ \\
\hline MS3 & $0.78 \pm 0.0 \mathrm{l}^{\mathrm{abf}}$ & $4.50 \pm 0.02$ & MS3I & $0.92 \pm 0.02^{\mathrm{fid}}$ & $4.40 \pm 0.02$ \\
\hline MS4 & $0.79 \pm 0.02^{\mathrm{abf}}$ & $4.51 \pm 0.02$ & MS32 & $0.89 \pm 0.02^{\mathrm{fid}}$ & $4.46 \pm 0.02$ \\
\hline MS5 & $0.72 \pm 0.0 \mathrm{I}^{\text {bec }}$ & $4.54 \pm 0.02$ & MS33 & $0.94 \pm 0.05^{\text {id }}$ & $4.33 \pm 0.02$ \\
\hline MS6 & $0.73 \pm 0.02^{\mathrm{abc}}$ & $4.55 \pm 0.02$ & MS34 & $\mathrm{I} .10 \pm 0.04^{\mathrm{hm}}$ & $4.15 \pm 0.02$ \\
\hline MS8 & $0.83 \pm 0.02^{\text {aef }}$ & $4.48 \pm 0.02$ & MS35 & $0.87 \pm 0.04^{\text {afid }}$ & $4.46 \pm 0.02$ \\
\hline MS9 & $0.87 \pm 0.02^{\text {afid }}$ & $4.45 \pm 0.01$ & MS36 & $\mathrm{I} .0 \mathrm{I} \pm 0.02^{\mathrm{md}}$ & $4.20 \pm 0.01$ \\
\hline MSIO & $0.74 \pm 0.02^{\mathrm{abc}}$ & $4.52 \pm 0.01$ & MS37 & $1.00 \pm 0.03^{\mathrm{md}}$ & $4.14 \pm 0.01$ \\
\hline MSII & $0.92 \pm 0.0 \mathrm{I}^{\text {fid }}$ & $4.41 \pm 0.02$ & MS38 & $1.10 \pm 0.06^{\mathrm{hm}}$ & $4.19 \pm 0.02$ \\
\hline MSI2 & $0.78 \pm 0.0 \mathrm{l}^{\mathrm{abf}}$ & $4.51 \pm 0.01$ & MS39 & $0.90 \pm 0.02^{\mathrm{fid}}$ & $4.36 \pm 0.01$ \\
\hline MSI3 & $0.61 \pm 0.02^{c}$ & $4.59 \pm 0.01$ & MS40 & $0.84 \pm 0.0 I^{\text {aefi }}$ & $4.43 \pm 0.01$ \\
\hline MSI4 & $0.68 \pm 0.03^{\mathrm{bc}}$ & $4.56 \pm 0.09$ & MS4I & $1.43 \pm 0.06^{r}$ & $3.92 \pm 0.09$ \\
\hline MSI5 & $0.66 \pm 0.0 \mathrm{I}^{\mathrm{bc}}$ & $4.57 \pm 0.01$ & MS42 & $1.40 \pm 0.05^{r}$ & $3.97 \pm 0.01$ \\
\hline MSI6 & $0.7 \mathrm{I} \pm 0.0 \mathrm{I}^{\mathrm{bec}}$ & $4.51 \pm 0.01$ & MS43 & $1.43 \pm 0.04^{r}$ & $3.86 \pm 0.01$ \\
\hline MSI7 & $0.71 \pm 0.02^{\text {bec }}$ & $4.52 \pm 0.09$ & MS44 & $1.37 \pm 0.04^{r}$ & $3.90 \pm 0.09$ \\
\hline MSI8 & $0.68 \pm 0.02^{b c}$ & $4.55 \pm 0.02$ & MS45 & $\mathrm{I} .00 \pm 0.0 \mathrm{I}^{\mathrm{md}}$ & $4.23 \pm 0.02$ \\
\hline MSI9 & $0.68 \pm 0.0 \mathrm{I}^{\mathrm{bc}}$ & $4.56 \pm 0.01$ & MS46 & $1.35 \pm 0.05^{r}$ & $3.99 \pm 0.01$ \\
\hline MS20 & $0.80 \pm 0.0 \mathrm{I}^{\mathrm{abfi}}$ & $4.50 \pm 0.01$ & MS47 & $1.12 \pm 0.04^{\mathrm{hm}}$ & $4.00 \pm 0.01$ \\
\hline MS2I & $\mathrm{I} .12 \pm 0.08^{\mathrm{hm}}$ & $4.00 \pm 0.07$ & MS48 & $1.38 \pm 0.09^{r}$ & $3.97 \pm 0.07$ \\
\hline MS22 & $0.88 \pm 0.02^{\mathrm{fid}}$ & $4.44 \pm 0.01$ & MS49 & $1.21 \pm 0.09 r$ & $3.99 \pm 0.01$ \\
\hline MS23 & $0.87 \pm 0.0 \mathrm{I}^{\text {afid }}$ & $4.45 \pm 0.01$ & MS50 & $1.29 \pm 0.10^{h}$ & $4.01 \pm 0.01$ \\
\hline MS24 & $0.7 \mathrm{I} \pm 0.0 \mathrm{I}^{\text {bec }}$ & $4.53 \pm 0.09$ & MS5I & $1.41 \pm 0.12^{r}$ & $3.96 \pm 0.09$ \\
\hline MS25 & $0.92 \pm 0.02^{\text {fid }}$ & $4.33 \pm 0.02$ & MS52 & $0.80 \pm 0.03^{b f i}$ & $4.49 \pm 0.07$ \\
\hline MS26 & $0.92 \pm 0.02^{\mathrm{fid}}$ & $4.39 \pm 0.01$ & MS53 & $0.78 \pm 0.0 \mathrm{I}^{\mathrm{abf}}$ & $4.49 \pm 0.10$ \\
\hline MS27 & $0.84 \pm 0.0 I^{\text {aefi }}$ & $4.47 \pm 0.01$ & MS54 & $0.96 \pm 0.0 \mathrm{l}$ id & $4.32 \pm 0.04$ \\
\hline MS28 & $0.94 \pm 0.02^{\mathrm{imd}}$ & $4.32 \pm 0.01$ & MS55 & $1.10 \pm 0.03^{\mathrm{hm}}$ & $4.23 \pm 0.04$ \\
\hline
\end{tabular}

Notes: *Absorbance values reached at the end of exponential growth phase were used for maximum bacterial population determinations. Bacterial growth was followed by $O D$ at $560 \mathrm{~nm}$ as described in the Materials and methods section. Values are the means of three independent experiments \pm standard deviation. Different letters within columns indicate significance with a $\mathrm{P}$ value $<0.05$ so values with the same letter in the same column are not significantly different $(P<0.05)$. Different times required to reach the end of exponential growth. Smaller time required was three days.

Abbreviations: MRS, deMan Rogosa Sharpe; TJ, tomato juice.

On the basis of its growth response, high enzymatic activity, and an adequate diacetyl, acetoin and 2,3-butilenglycol production, the MS25 strain was selected for further investigations concerning to the influence of some wine parameters on its growth and biochemical activities studied.

\section{Effect of $\mathrm{pH}$ and L-malic acid on growth and carbon source utilization}

As shown in Table 4 the growth and carbon sources utilization by $O$. oeni MS25 was investigated in MRS medium with $\mathrm{TJ}$ under the following condition: absence or presence of L-malate $(2.5 \mathrm{~g} / \mathrm{l})$ at two initial $\mathrm{pH}$ values: 4.8 and 3.8. At $\mathrm{pH} 4.8$ (control), the microorganism grew with a growth rate of 0.067 and with a final $\mathrm{OD}_{560 \mathrm{~nm}}$ above one. L-malic acid increased both growth parameters of about $13 \%$ and $36 \%$, respectively. Similar results were observed by Saguir and Manca de $\mathrm{Nadra}^{11,27}$ and Aredes Fernandez and colleagues. ${ }^{28}$ When the initial $\mathrm{pH}$ was adjusted at 3.8, growth rate and final biomass of the MS25 strain significantly decreased. L-malic acid again stimulated growth parameters. At $\mathrm{pH} 4.8$, between $80 \%-70 \%$ of initial glucose was exhausted depending of the L-malic acid presence. At $\mathrm{pH} 3.2$, the sugar consumption, was in a lesser extent than at 4.8. In this condition the organic acid enhanced glucose utilization as well as bacterial growth. L-malic was completely utilized at $\mathrm{pH} 4.8$ and more than $80 \%$ at $\mathrm{pH} 3.8$. 
Table $2 \beta$-glucosidase activities ( $\mathrm{U} / \mathrm{g})$ in whole cells of the Oenococcus oeni isolates obtained from MRS medium with TJ (I5\%) at the end of exponential growth phase ${ }^{a}$

\begin{tabular}{|c|c|c|c|c|c|}
\hline \multirow{2}{*}{\multicolumn{2}{|c|}{ Strain $\leq$ than 20}} & \multicolumn{4}{|c|}{$\beta$-glucosidase activity (U/g) } \\
\hline & & \multicolumn{2}{|c|}{ Strain between 20 to 60} & \multicolumn{2}{|c|}{ Strain $\geq$ than 60} \\
\hline Control $^{b}$ & 0 & MS4 & $53.00 \pm 4.04$ & MSI5 & $70.01 \pm 6.59$ \\
\hline MS3 & $18.4 \pm 0.95$ & MS6 & $46.25 \pm 4.02$ & MS20 & $80.82 \pm 3.50$ \\
\hline MS5 & $19.73 \pm 0.67$ & MS7 & $43.55 \pm 0.61$ & MS24 & $64.54 \pm 4.36$ \\
\hline MS22 & $3.20 \pm 0.38$ & MS9 & $39.10 \pm 0.21$ & MS25 & $128.35 \pm 7.84$ \\
\hline MS23 & $6.29 \pm 0.54$ & MSIO & $51.20 \pm 1.41$ & MS48 & $60.49 \pm 1.92$ \\
\hline MS27 & $9.39 \pm 0.45$ & MSI7 & $41.90 \pm 2.22$ & MS49 & $89.80 \pm 0.69$ \\
\hline MS28 & $4.94 \pm 0.12$ & MS30 & $46.06 \pm 3.21$ & MS50 & $69.54 \pm 1.62$ \\
\hline MS29 & $6.70 \pm 0.58$ & MS3I & $28.32 \pm 2.11$ & MS5I & $115.60 \pm 8.77$ \\
\hline MS33 & $18.74 \pm 1.2$ & MS32 & $47.13 \pm 3.24$ & MS52 & $114.93 \pm 9.72$ \\
\hline MS33 & $18.74 \pm 1.2$ & MS35 & $33.30 \pm 3.04$ & & \\
\hline MS36 & $1.98 \pm 0.04$ & MS46 & $53.86 \pm 5.13$ & & \\
\hline MS39 & $1.02 \pm 0.89$ & MS47 & $42.48 \pm 3.11$ & & \\
\hline MS40 & $8.06 \pm 0.51$ & MS53 & $43.32 \pm 3.93$ & & \\
\hline MS4I & $8.60 \pm 1.39$ & MS54 & $36.09 \pm 1.28$ & & \\
\hline
\end{tabular}

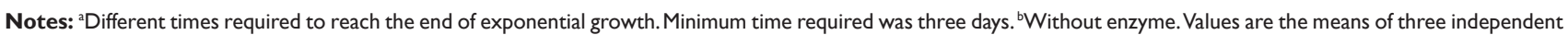
experiments \pm standard deviation.

Abbreviations: MRS, deMan Rogosa Sharpe; TJ, tomato juice.

\section{Effect of $\mathrm{pH}$ and/or L-malic acid on enzyme activity and aroma compounds production}

Oenococcus oeni MS25 strain appeared able to hydrolyze $p$-NPG under all conditions assayed. However, $\beta$-glucosidase activity was positively and negatively influenced by L-malic acid and $\mathrm{pH}$, respectively ranged between 174.2 to $31.2 \mathrm{U} / \mathrm{g}$. At pH 4.8 (control medium), L-malic acid addition markedly increased the activity and it was maximum. By contrast, at pH 3.8 the lowest activity was detected $(65 \%$ lower than at $\mathrm{pH} 4.8$ ). In this condition, L-malic acid stimulated about $10 \%$ the enzymatic activity, but it was not enough to annul completely the loss of activity compared with that obtained at $\mathrm{pH} 4.8$ (Figure 4).

The initial $\mathrm{pH}$ and/or L-malic acid affected negatively the diacetyl, acetoin and 2,3-butilenglycol production by the MS25 strain as regards to the control medium. The more pronounced effect was observed at $\mathrm{pH} 3.8$ and in presence of L-malic acid (Figure 4).

\section{Discussion}

Despite the overall significance of LAB in wine production, there are only occasional reports of their isolation from juice grape. In our study numbers of LAB found in grape juice (approximately $\log _{10} 3.3$ ) was in accordance with the results reported by du Plessis and colleagues. ${ }^{29}$ Lower LAB population was found in grape juice than in the samples from commencement of MLF. This fact may be related with the inability of LAB to compete efficiently with the yeasts and non-LAB population present in the natural medium, or to the metabolic products such as ethanol, $\mathrm{SO}_{2},{ }^{30}$ medium-chain fatty acids excreted by yeasts ${ }^{31}$ and/or intracellular and extracellular cationic proteins..$^{32}$ In addition, Bae and colleague ${ }^{26}$ demonstrated that in wine grapes initial LAB populations were very low and less than $10^{2} \mathrm{cfu} / \mathrm{gram}$. On the other hand at the stage corresponding at commencement of MLF the LAB growth could be helped by the increase in yeast lysis products.

No significant difference in the LAB count between the two samples from beginning of MLF occurred. However, Reguant and colleagues, ${ }^{33}$ reported that the LAB population of the wines that had been inoculated with yeast strain $\mathrm{C} 2$ decreased at the end of the $\mathrm{AF}$ as regards other vinification without it, indicating that the yeast starter culture might have controlled the LAB development.

In grape juice non-LAB presumibly identified as acetic acid bacteria were isolated. The species Asaia siamensis considered within the genera of acetic acid bacteria was isolated from wines grapes. ${ }^{26}$ No analyzed samples gave detectable Enterobacteriaceae. Either they were absent in the grape juice and wines samples or they were overgrown by other species during isolation. 


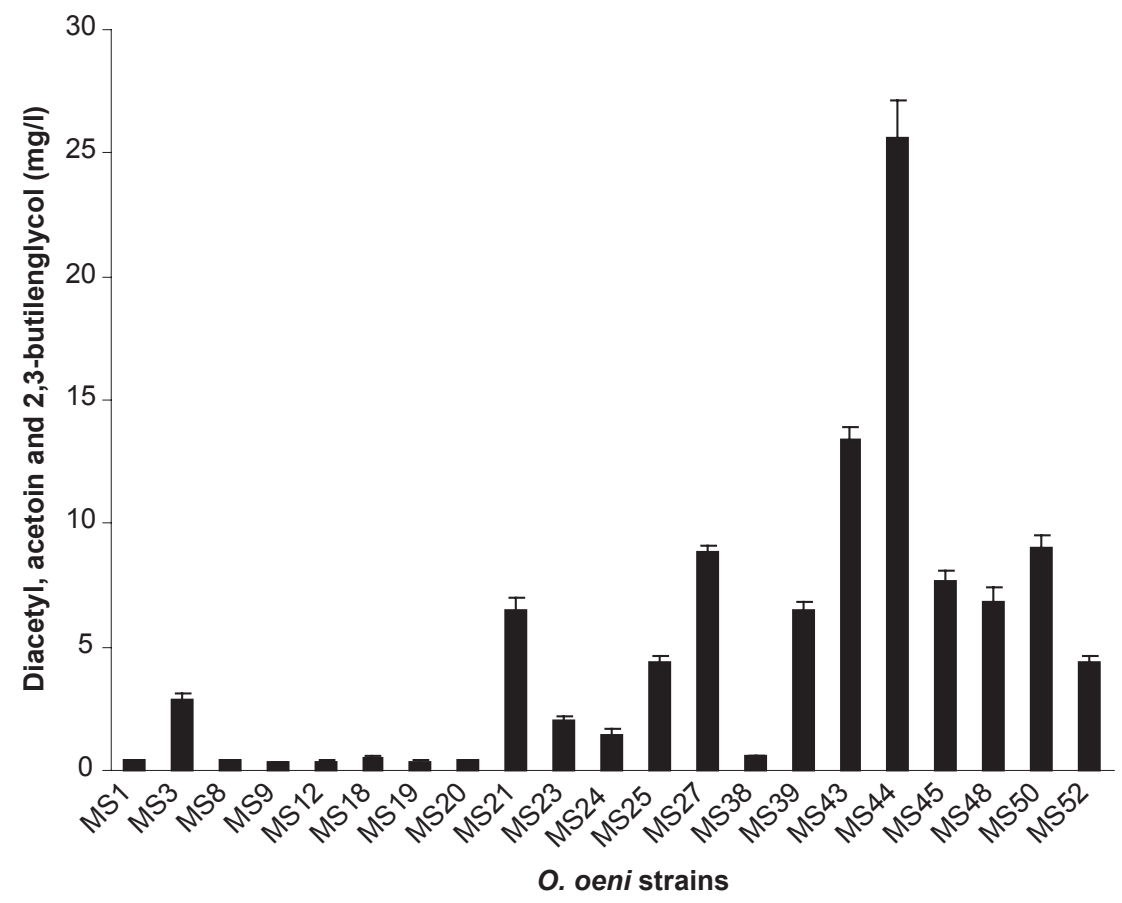

Figure 3 Diacetyl, acetoin or 2,3-butilenglycol production by the Oenococcus oeni isolates in MRS medium with TJ, I5\%, measured at the end of exponential growth. Oenococcus oeni strains that did not exhibit the aroma compounds formation were not included in the graph.

Abbreviations: MRS, deMan Rogosa Sharpe; TJ, tomato juice.

Oenococcus oeni was the most dominant species among the LAB isolates, accounting for $68 \%$ of the total isolated strains. However, in grape juice other LAB species than O. oeni was the dominant species. This fact could be related with its numerous nutritional requirements for development. It was demonstrated that the majority of amino acids were stimulatory or essential for its growth. ${ }^{28,32,34}$ Thus, the decreased growth of $O$. oeni in the natural juice could be due to a nutritional competition. On the other hand the predominance of $O$. oeni at the beginning of MLF (representing $79.6 \%$ of the total of $\mathrm{LAB}$ isolates), has been also reported in other wines. ${ }^{1,4,33}$ du Plessis and colleagues ${ }^{5}$ described that Lactobacillus plantarum were the dominating species in the grape juice, but their viability decreased significantly during $\mathrm{AF}, O$. oeni being the dominating species in 15 of the 23 base wine samples that had undergone spontaneous MLF.

By comparing results obtained from growth responses of $O$. oeni isolates, phenotypical and genotypically were identified, in MRS medium with TJ, we observed that coincidently the lowest final biomass corresponded to isolates from grape juice, where $O$. oeni faced the highest development difficulties.

Studies investigated about the glycosidase activities of $O$. oeni, but an extensive screening including more than 45 wild strains of this species is reported here for the first time. $\beta$-glucosidase activities from whole cells of $O$. oeni isolates measured at the end of the exponential growth phase

Table 3 Proportion of Oenococcus oeni strains from grape juice and fermented musts in the different groups according to the levels of enzyme and aroma compounds produced

\begin{tabular}{|c|c|c|c|c|}
\hline \multirow{3}{*}{$\begin{array}{l}\text { Diacetyl }(\mathrm{mg} / \mathrm{l}) \\
\text { Levels }\end{array}$} & \multicolumn{4}{|c|}{ Proportion of strains (\%) } \\
\hline & \multicolumn{4}{|c|}{$\beta$-glucosidase activity (U/g) } \\
\hline & Not detected & Low $(I-20)$ & Intermediary $(>20-60)$ & High $(>60)$ \\
\hline Not detected & 13 & 14.8 & 28 & 5.5 \\
\hline$\geq 0.23 \pm 0.04$ to $\leq 4.4 \pm 0.22$ & 7.4 & 5.5 & 3.7 & 7.4 \\
\hline$>4.4 \pm 0.22$ to $\leq 8.9 \pm 0.26$ & 3.7 & 3.7 & 0 & 1.8 \\
\hline$\geq 9 \pm 0.49$ & 3.7 & 0 & 0 & 1.8 \\
\hline
\end{tabular}

Notes: Values are the means of three independent experiments \pm standard deviation. 
Table 4 Influence of L-malic acid and initial pH on the maximum population and growth rate of Oenococcus oeni MS25 and on the residual glucose and L-malic acid of cultures

\begin{tabular}{|c|c|c|c|c|c|}
\hline Culture medium & Initial pH & $\begin{array}{l}\text { Maximum } \\
\text { population }^{\text {b }}\end{array}$ & $\begin{array}{l}\text { Growth rate } \\
(\mu)\end{array}$ & $\begin{array}{l}\text { Glucose } \\
(\mathrm{g} / \mathrm{l})\end{array}$ & $\begin{array}{l}\text { L-malic acid } \\
(\mathrm{g} / \mathrm{l})\end{array}$ \\
\hline MRS + TJ (CM) & 4.8 & $0.95 \pm 0.06$ & $0.067 \pm 0.004$ & $5.10 \pm 0.42$ & ND \\
\hline CM + L-malate & & $1.30 \pm 0.43$ & $0.076 \pm 0.004$ & $4.34 \pm 0.23$ & 0 \\
\hline MRS + TJ (MCM) & 3.8 & $0.55 \pm 0.09$ & $0.049 \pm 0.002$ & $8.80 \pm 0.51$ & ND \\
\hline MCM + L-malate & & $0.72 \pm 0.02$ & $0.056 \pm 0.002$ & $7.13 \pm 0.38$ & $0.43 \pm 0.02$ \\
\hline
\end{tabular}

Notes: anitial glucose and L-malic acid concentrations in MRS + TJ, 15\% media (CM or MCM) were 20 and $2.5 \mathrm{~g} / \mathrm{l}$, respectively. ${ }^{\mathrm{b}} \mathrm{Abs}$.rbance values reached at the end of exponential growth phase were used for maximum bacterial population determinations. Bacterial growth was followed by OD at $560 \mathrm{~nm}$. 'Growth rate was calculated during the exponential phase of growth on at least three linear points determined by plotting the data as $\operatorname{Ln}\left(O D_{560} n m\right)$ as a function of time of culture. Values are the means of three independent experiments $\pm S D$.

Abbreviations: CM, culture medium; MCM, maximum culture medium; MRS, deMan Rogosa Sharpe; SD, standard deviation; TJ, tomato juice.

demonstrated a range of capabilities. It is interesting to note that the majority of cells produced a detectable activity. By contrast, Barbagallo and colleagues ${ }^{19}$, demonstrated that only six out of 11 strains of $O$. oeni studied possessed this activity. However, Grimaldi and colleagues ${ }^{35}$ detected activity in all cultures derived from 11 commercial preparations of $O$. oeni. In this study, nevertheless $\beta$-glucosidase activity varied according to the strain, we consider that its distribution was quite uniform under assayed conditions, since activity was observed in more than $60 \%$ of whole cells, and they produced intermediary or low levels accounting for $74.3 \%$ of the total of positive cells for this activity. Strains showing high enzymatic activity were found in the lowest extent and they were isolated from the begining in MLF samples, so this first screening for $\beta$-glucosidase activity is very important for selection in further investigations. On the other hand, Bloem and colleagues ${ }^{36}$ reported that glycosylated precursors in oak wood are different from those obtained in grape glycosylated precursors, which are bound with a $\beta$-D-glucose. So, the further study of other glucosidic enzymes such as $\alpha$-L-rhamnopyranosidase and $\alpha$-L-arabinofuranosidase is necessary to complete this first characterization.

An interesting finding was that the highest proportion of $O$. oeni population $(61 \%)$ did not possess the capacity to produce diacetyl, acetoin, and 2,3-butilenglycol, contrary to that observed for $\beta$-glucosidase activty. Saguir and Manca de $\mathrm{Nadra}^{9,27}$ reported that in one $O$. oeni strain from wine, that no diacetyl, acetoin, 2,3-butilenglycol were found during growing in a complete or N-deficient synthetic media. In our study no direct relation among the $O$. oeni isolates for both biochemical activities could be clearly established. Thus, strains that failed to form the aroma compounds were able to produce different levels of $\beta$-glucosidase activity. On the other hand, strains producing the highest concentrations of aroma compounds mainly failed in their enzymatic activities and only a lesser proportion possessed high activity (Table 3). However, considering the relation between the vinification steps, in which the $O$. oeni strains were isolated with the biochemical properties studied of each one, we can establish that both $\beta$-glucosidase activity as $\mathrm{C}_{4}$ aroma compounds formation occurred at a higher frequency in isolated strains from beginning of MLF than grape juice.

It was particularly interesting that the selected MS25 strain was able to grow at $\mathrm{pH}$ 3.8. In addition L-malic acid stimulated its growth. This result was in agreement with previous studies for which a stimulating effect of $\mathrm{L}$-malate was observed at $\mathrm{pH}$ 4.8 or below. ${ }^{9,37}$ Higher values of final $\mathrm{pH}$ in the media with L-malic acid than without it (data not shown) would be related with the dicarboxylic acid utilization by the MS25 strain. The fact that L-malic acid was totally consumed at $\mathrm{pH} 4.8$ and more than $80 \%$ at $\mathrm{pH} 3.8$ is of particular importance for considering the use of the MS25 strain on wine. Augagneur and colleagues ${ }^{37}$ demonstrated that L-malate utilization contributed to the generation of a high $\Delta \mathrm{pH}$. They also reported that under low $\mathrm{pH}$ conditions the decrease of $\Delta \psi$, that controls the rate of transport/ fermentation coupled with an increased of the $\Delta \mathrm{pH}$ that drives the transport, contributes to an increased fermentation rate. In O. oeni MS25 growing at $\mathrm{pH} 4.8$ in presence of L-malic acid, significant difference in glucose consumption was determined in accordance with the higher biomass production.

L-malic acid stimulated $\beta$-glucosidase activity in all conditions, but the initial $\mathrm{pH} 3.8$ had a negative effect on it, despite maintaining a significative enzyme production.

The assays at $\mathrm{pH} 3.8$ and/or with L-malic acid showed a decreased production of $\mathrm{C}_{4}$ aroma compounds as regards to those obtained at $\mathrm{pH} 4.8$. Nielsen and Richelieu ${ }^{38}$ reported that the range of $\mathrm{pH}$ values previously recommended for diacetyl production by LAB in various fermented foods was 4.3-4.7.

In conclusion, $O$. oeni was the dominant species among the total of the LAB isolates. The results of screening indicated that the majority of whole cells showed detectable $\beta$-glucosidase activity at the end of exponential growth. 


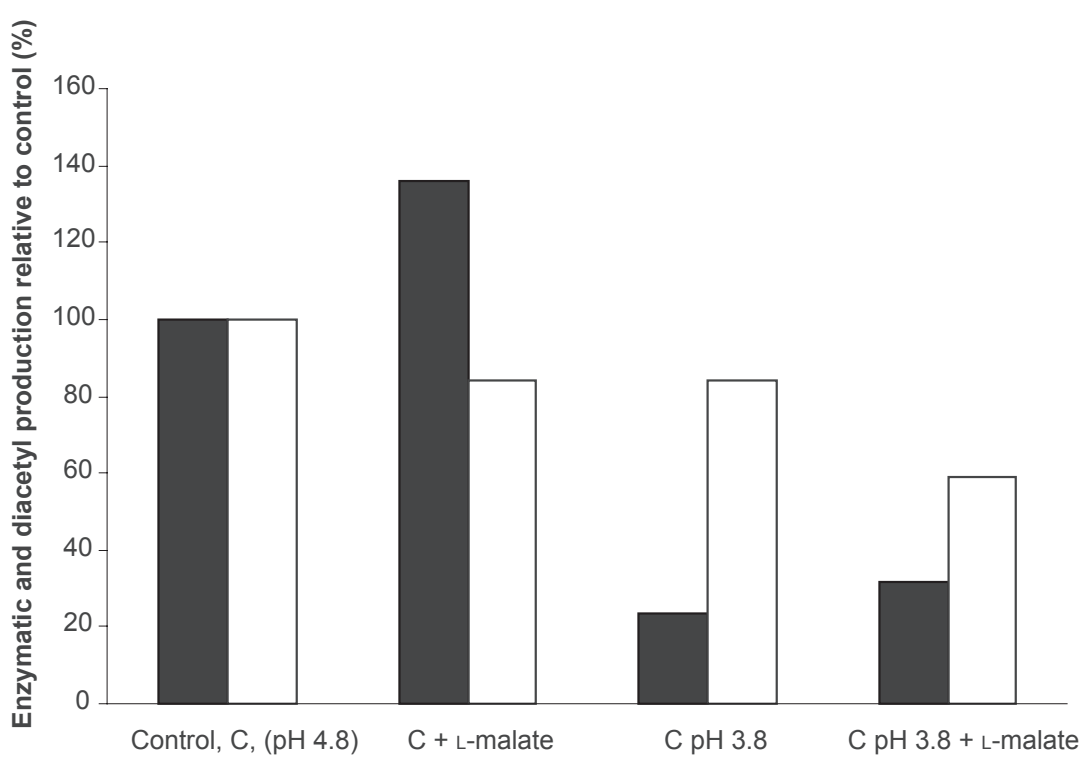

Culture media

Figure 4 Influence of $\mathrm{pH}$ and/or L-malic acid on the $\beta$-glucosidase activity and diacetyl production measured in whole cells and supernatant of cultures, respectively at the end of exponential growth phase in Oenococcus oeni MS25.

Contrarily the highest proportion of them did not produce diacetyl, acetoin and 2,3-butilenglycol. In the selected MS25 strain the findings indicated that L-malic acid is compatible with a good level of enzyme activity and in part able to annul the negative influence of low $\mathrm{pH}$. In different conditions the aroma compounds were lower than $4 \mathrm{mg} / \mathrm{ml}$, especially at pH 3.8 and in presence of L-malic acid. So this strain would have adequate characteristics for potential use in winemaking, although more experiments are needed to confirm it. Finally, from these results we considerer that the assessment of both biochemical properties studied in the $O$. oeni strains should be taken in account as a quality criterion of selecting starter cultures for the improvement of the organoleptic properties of wines, although further experiments are needed to confirm it.

\section{Acknowledgments}

This work was supported by grants from Consejo Nacional de Investigaciones Científicas y Técnicas (CONICET) and Consejo de Investigaciones de la Universidad Nacional de Tucumán (CIUNT), Argentina and Agencia Nacional de Promoción Científica y Tecnológica. The authors report no conflicts of interest in this work.

\section{References}

1. Lonvaud-Funel A. Lactic acid bacteria in the quality improvement and depreciation of wine. Antonie Van Leeuwenhoek. 1999;76:317-331.

2. Du Toit M, Pretorius IS. Microbial spoilage and preservation of wine: Using weapons from Nature's own arsenal-a review. S Afr J Enol Vitic. 2000;21:74-96.
3. Edwards CG, Collins MD, Lawson PA, Rodriguez AV. Lactobacillus nagelii sp. nov., an organism isolated from a partially fermented wine. Int J Syst Evol Microbiol. 2000;50:699-702.

4. Reguant C, Bordons A. Typification of Oenococcus oeni strains by multiplex RAPD-PCR and study of population dynamics during malolactic fermentation. J Appl Microbiol. 2003;95:344-353.

5. du Plessis HW, Dicks LMT, Pretorius IS, Lambrechts MG, du Toit M. Identification of lactic acid bacteria isolated from South African brandy base wines. Int J Food Microbiol. 2004;91:19-29.

6. Kunkee RE. Some roles of L-malic acid in the malolactic fermentation in wine making. FEMS Microbiol Rev. 1998;8:55-72.

7. Laurent MH, Henick-Kling T, Acree TE. Changes in the aroma and odor of Chardonnay due to malolactic fermentation. Wein-Wiss. 1994;49:3-10.

8. Bartowsky EJ, Henschke PA. The 'buttery' attribute of wine - diacetyl desirability, spoilage and beyond. Int J Food Microbiol. 2004;96:235-252.

9. Saguir FM, Manca de Nadra MC. Effect of L-malic and citric acids metabolism on the essential amino acid requirements for Oenococcus oeni growth. J Appl Microbiol. 2002;93:295-301.

10. Martineau B, Henick-Kling T. Performance and diacetyl production of commercial strains of malolactic bacteria in wine. J Appl Bacteriol. 1995; 78:526-536.

11. Le Traon-Masson MP, Pellerin P. Purification and characterization of two $\beta$-D-glucosidases from an Aspergillus niger enzyme preparation. Affinity and specificity toward glucosylated compounds characteristic of the processing of fruits. Enzyme Microbiol Tech. 1998;22:374-382.

12. Günata ZY, Bitteur S, Brillouet JM, Bayonove C, Cordonnier RE. Sequential enzymatic hydrolysis of potentially aromatic glycosides from grapes. Carbohydr Res. 1988;134:139-149.

13. D'Incecco N, Bartowsky E, Kassarab S, Lantea A, Spettolia P, Henschkeb P. Release of glycosidically bound flavour compounds of Chardonnay by Oenococcus oeni during malolactic fermentation. Food Microbiol. 2004;21:257-265.

14. McMahon H, Zoecklein BW, Fugelsang K, Jasinsky Y. Quantification of glycosidase activities in selected yeasts and lactic acid bacteria. $J$ Ind Microbiol Biotechnol. 1999;23:198-203.

15. Spagna G, Barbagallo RN, Greco E, Manenti I, Pifferi PG. A mixture of purified glycosidases from Aspergillus niger for oenological application immobilised by inclusion in chitosan gels. Enzyme Microbiol Technol. 2002;30:80-89. 
16. Aryan AP, Wilson B, Strauss CR, et al. The properties of glycosidases of Vitis vinifera and comparison of their $\beta$-glycosidase activity with that of exogenous enzymes. An assessment of possible applications in enology. Am J Enol Vitic. 1987;38:182-188.

17. Boido E, Lloret A, Medina K, Carrai F, Della Cassa E. Effect of $\beta$-glycosidase activity of Oenococcus oeni on the glycosylated flavor precursors of Tannat wine during malolactic fermentation. J Agric Food Chem. 2002;50:2344-2349.

18. Mansfield AK, Zoecklein BW, Whiton RS. Quantification of glycoside activity in selected strains of Brettanomyces bruxellensis and Oenococcus oeni. Am J Enol Vitic. 2002;53:303-307.

19. Barbagallo RN, Spagna G, Palmeri R, et al. Assessment of $\beta$-glucosidase activity in selected wild strains of Oenococcus oeni for malolactic fermentation. Enzyme Microb Technol. 2004;34:292-296.

20. Devriese LA, Pot B, Collins MD. Phenotypic identification of the genus Enterococcus and differentiation of phylogenetically distinct enterococcal species and species group. J Appl Bacteriol. 1993;75:399-408.

21. Gibson T, Abdel-Malek Y. The formation of carbon dioxide by lactic acid bacteria and Bacillus licheniformis and a cultural method of detecting the process. J Dairy Res. 1945;14:35-44.

22. Zapparoli G, Torriani S, Pesente P, et al. Design and evaluation of malolactic enzyme gene targeted primers for rapid identification and detection of Oenococcus oeni in wine. Lett Appl Microbiol. 1998;27:243-246.

23. Hill EC, Wenzel FW, Barreto A. Colorimetric method for the microbiological spoilage in citrus juices. Food Technol. 1954;8:168-171.

24. Branen AL, Keenan TW. Diacetyl reductase of Lactobacillus casei. Can J Microbiol. 1970;16:947-951.

25. Rossman AJ, Chance BL. Workshop Statistics: Discovery with Data and Minitab. New York, NY: Springer; 1998.

26. Bae S, Fleet GH, Heard GM. Lactic acid bacteria associated with wine grapes from several Australian vineyards. J Appl Microbiol. 2006;100: $712-727$.

27. Saguir FM, Manca de Nadra MC. Organic acids metabolism under different glucose concentrations of Leuconostoc oenos from wine. J Appl Bacteriol. 1996;81:393-397.
28. Aredes Fernandez PA, Saguir FM, Manca de Nadra MC. Effect of dipeptides on the growth of Oenococcus oeni in synthetic medium deprived of amino acids. Curr Microbiol. 2004;49:361-365.

29. du Plessis HW, Steger CLC, du Toit M, Lambrechts MG. The occurrence of malolactic fermentation in brandy base wine and its influence on brandy quality. J Appl Microbiol. 2002;92:1005-1013.

30. Lemaresquier H. Inter-relationships between strains of Saccharomyces cerevisiae from the Champagne area and lactic acid bacteria. Lett Appl Microbiol. 1987;4:91-94.

31. Lafon-Lafourcade S, Genix C, Ribereau-Gayon P. Inhibition of alcoholic fermentation of grape must by fatty acids produced by yeasts and their elimination by yeast ghosts. Appl Environ Microbiol. 1984;47: 1246-1249.

32. Comitini F, Ferretti R, Clementi F, Mannazzu I, Ciani M. Interactions between Saccharomyces cerevisiae and malolactic bacteria: preliminary characterization of a yeast proteinaceous compound(s) active against Oenococcus oeni. J Appl Microbiol. 2005;99:105-111.

33. Reguant C, Carreté R, Constantí M, Bordons A. Population dynamics of Oenococcus oeni strains in a new winery and the effect of $\mathrm{SO}_{2}$ and yeast strain. FEMS Microbiol Lett. 2005;246:111-117.

34. Amoroso MJ, Saguir FM, Manca de Nadra MC. Variation of nutritional requirements of Leuconostoc oenos by organic acids. J Inter Sci Vigne Vin. 1993;27:135-144.

35. Grimaldi A, McLean H, Jiranek V. Identification and partial characterization of glycosidic activities of commercial strains of the lactic acid bacterium, Oenococcus oeni. Am J Enol Vitic. 2000;51:362-369.

36. Bloem A, Lonvaud-Funel A, de Revel G. Hydrolysis of glycosidically bound flavour compounds from oak wood by Oenococcus oeni. Food Microbiol. 2008;825:99-104.

37. Augagneur Y, Ritt JF, Linares DM, et al. Dual effect of organic acids as a function of external $\mathrm{pH}$ in Oenococcus oeni. Arch Microbiol. 2007; 188:147-157.

38. Nielsen JC, Richelieu M. Control of flavor development in wine during and after malolactic fermentation by Oenococcus oeni. Appl Environ Microbiol. 1999;65:740-745.
International Journal of Wine Research

\section{Publish your work in this journal}

The International Journal of Wine Research is an international peer-reviewed open-access, online journal focusing on all scientific aspects of wine, including: vine growing; wine elaboration; human interaction with wine; and health aspects of wine The journal provides an open access platform for the reporting

\section{Dovepress}

of evidence based studies on these topics. The manuscript management system is completely online and includes a very quick and fair peer-review system, which is all easy to use. Visit http://www.dovepress.com/testimonials.php to read real quotes from some of our published authors 